\title{
Projecções cinematographicas: o cinema nas crônicas do pré- modernismo brasileiro
}

\author{
Maurício Silva ${ }^{1}$
}

\begin{abstract}
RESUMO: O presente artigo analisa a representação do cinema na literatura brasileira prémodernista (contos, crônicas, romances e poesia), numa época em que o cinema estava apenas iniciando seu longo percurso no cenário cultural brasileiro. Trata-se, portanto, de uma abordagem, por meio da cultura e da história, do processo de modernização da cidade e da sociedade brasileiras.
\end{abstract}

PALAVRAS-CHAVE: Cultura brasileira. Literatura pré-modernista. Cinema. Modernização.

\section{Introdução}

A passagem do século $X I X$ para o século $X X$ foi, em todo o mundo ocidental, palco das mais diversas e inesperadas transformações, que, observadas pela ótica distanciada da historiografia retrospectiva, trouxeram consequências inevitáveis ao desenvolvimento de nossa cultura. A complexidade do período foi, aliás, percebida pelos próprios protagonistas dessas transformações, que não hesitaram em classificá-lo, segundo a perspectiva adotada, com as designações de Belle Époque, Fin-de-Siècle, Decadentismo ou Paz Armada. E se todos esses conceitos buscam, bem ou mal, refletir um aspecto preciso da realidade circundante, nenhum deles consegue, contudo, abarcar integralmente sua estonteante complexidade, sobretudo se considerarmos os desdobramentos que conflitos claros ou latentes acabaram ocasionando a posteriori, dos quais a Primeira Guerra Mundial parece ser um índice inequívoco (BOURGIN, 1967; WEBER, 1989).

No Brasil, onde o universo cultural quase sempre mostrou-se propenso às influências estrangeiras, houve como que uma importação dos valores cultuados durante a Belle Époque, transferindo para o ambiente nativo, senão todas, pelo menos a maior parte das conquistas e achados europeus durante os anos que mediaram fins do século XIX e começo do XX, engendrando uma sugestiva

\footnotetext{
${ }^{1}$ Doutor em Letras pela Universidade de São Paulo. Professor da Universidade Nove de Julho (São Paulo. E-mail: maurisil@gmail.com
} 
espécie de Belle Époque tropical (NEEDELL, 1993). Esse foi, aliás, um processo que herdamos do próprio período colonial: com efeito, a passagem, no Brasil, do regime monárquico para o republicano marca mais do que uma transformação política e econômica de larga amplitude: inaugura, sobretudo, uma nova mentalidade, que se desenvolve de modo infrene e algo anárquica, mas que coloca o país em novos e inesperados rumos da modernização.

Trata-se de uma transformação que já vinha sendo gestada há algum tempo e que não pode ser imputada a um único e determinado grupo social ou político. O Brasil "moderno", nesse sentido, conheceu variadas e diferentes facetas e passou pelas mais diversas etapas, além de ter sido o resultado de um processo ininterrupto e complexo, que dependeu, em parte, da vontade pessoal de alguns dos nossos principais dirigentes políticos, mas também de uma intrincada rede de engrenagens socioeconômicas forjadas desde pelo menos meados do século XIX e que contribuiu decisivamente para o estabelecimento de um franco processo de modernização da sociedade brasileira.

Talvez nenhum fenômeno cultural tenha conseguido revelar semelhante transformação com tanta largueza de espírito como a literatura e, numa versão mais "profissional" das letras, o jornalismo. Romances, contos, poemas, peças teatrais ou crônicas mundanas, tudo acabou sendo influenciado pelo ímpeto modernizador por que passava o país, dando ensejo a uma série infindável de análises das insólitas transformações do cenário nacional. Boa parte dos literatos e dos jornalistas - não poucas vezes confundidos numa só pessoa - tornaram-se os arautos dos tempos modernos, e pareciam gabar-se dessa condição inusitada. Quase todos, portanto, assistiam atônitos às cenas desse espetáculo feérico, e o próximo ato era sempre marcado pela surpreendente imprevisibilidade. Nada se revelava demasiadamente estável, seguro, definitivo, e a própria vida social parecia ter-se deixado ficar, de repente, em suspenso.

$\mathrm{E}$, em se tratando, como falamos, de espetáculo feérico, o cinema despontava como uma das grandes descobertas da modernidade ocidental.

Falando sobre os primórdios do cinema no Brasil, Vicente de Paula Araújo lembra que já em 1896, um ano depois de os irmãos Lumière patentearem na Europa um aparelho que ocasionaria o aparecimento do cinematógrafo, o Brasil recebia uma adaptação daquele instrumento, que passava a ser conhecido, no 
Rio de Janeiro, pela denominação de omniographo; em 1897, o português Aurélio da Paz dos Reis trazia ao Brasil o kinetographo, outro aparelho de imagens animadas, próximo à invenção de Lumière; finalmente, o verdadeiro Cinematographo Lumière seria apresentado aos brasileiros, nesse mesmo ano, pelo francês Henry Picolet, simultaneamente à exibição do Animatographo Lumière, dos brasileiros Paschoal Segreto e José Roberto Cunha Sales. O Rio de Janeiro passava por grandes transformações urbanas, e o cinematógrafo participava tanto das inaugurações (como a do eixo da Avenida Central) quanto das demolições (como a do Morro do Castelo). Em 1907, portanto, o cinema já conhecia um relativo sucesso e transformar-se-ia, em pouco tempo, na nova diversão popular do carioca (ARAÚJO, 1976).

Motivo de comentários e apreciações nas colunas de jornais da época, na pena de jornalistas como João do Rio (na seção "Cinematografo") e Figueiredo Pimentel (na seção "Binóculo"), ambas da Gazeta de Notícias, o cinema torna-se assunto recorrente de alguns literatos também, como Coelho Neto, Afrânio Peixoto, Humberto de Campos, Benjamin Costallat e outros. Entre os jornalistas, além dos dois já citados, surge com frequência na pena de João Luso, Antonio Torres, Filinto de Almeida, Gomes Leite, Augusto de Lima e Bastos Tigre. Assim, o cinema brasileiro - fenômeno que segue, de perto, um dos mais constantes dilemas brasileiros, que é o de se situar entre um localismo de cunho nacionalista (BERNARDET, 1993) e um universalismo de cunho moderno (FABRIS, 1994) -, passa, de modo compulsório, a fazer parte também do cenário das letras nacionais, não apenas sofrendo influência direta de nossa tradição literária, ao longo de seu desenvolvimento, mas também incidindo, de maneira indireta, na constituição de nossa literatura (SÜSSEKIND, 1987).

\section{O cinema na literatura pré-modernista brasileira}

Com efeito, o cinema aparece representado em muitos contos, crônicas, romances e mesmo em algumas poesias da época. Se atentarmos apenas para o caso dos romances, gênero que, como poucos, torna-se quase prevalente no período, vamos perceber que, já nos primeiros anos do século $\mathrm{XX}$, o cinema 
passara a fazer parte naturalmente do cotidiano brasileiro nas principais capitais do país.

É interessante perceber, por exemplo, que, embora relativamente recente, o mundo do cinema já se faz presente como motivo literário ou apenas como cenário para algum fato episódico, nos mais distintos romancistas: seja no acadêmico baiano Afrânio Peixoto, em seu melancólico e dramático As Razões do Coração (1925), seja na polígrafa Júlia Lopes de Almeida, com o Pássaro Tonto (1934), seja ainda no irreverente Benjamim Costallat, com seu romance, de sugestivo título, Mlle. Cinema (1923). Ressalte-se que, em boa parte dessa produção, o cinema era discutido em meio a digressões acerca da moralidade/liberalidade da sociedade carioca moderna, sobretudo numa época em que o espaço público passa a vigorar sobre o privado, fazendo com que as famílias burguesas procurassem os lazeres exteriores, como as festas populares, as praças, os jardins, os teatros e, last but not least, as salas de cinema, despertando para o que já se chamou de a vocação do prazer. "a cidade modernizada estimulou a família a usufruir do espaço público tornando-a mais consciente de seus direitos de circular na rua com segurança, numa atmosfera saudável onde pudesse passar boa parte das suas horas de lazer" (ARAÚJO, 1993, p. 332).

Nas crônicas, esse fenômeno se repete: muito mais apropriadas para registrar os instantâneos do cotidiano urbano, são elas que revelarão, no calor da hora, as transformações pelas quais as cidades estão passando e - no que aqui nos interessa - o alcance do cinema nessa dinâmica citadina. Nesse sentido, três são os cronistas que, com mais agudeza e perspicácia, souberam apreender e compreender a importância desse novo suporte tecnoartístico de veiculação daquilo a que já se deu o nome de uma arte fácil (METZ, 2004): Coelho Neto, Elysio de Carvalho e João do Rio.

Natural do estado do Maranhão, Henrique Maximiano Coelho Neto (18641934) foi um de nossos mais produtivos escritores, tendo, logo cedo, se afirmado como romancista, cronista, dramaturgo, poeta etc. Um dos fundadores da Academia Brasileira de Letras, tornou-se verdadeira referência literária em vida, vindo a ser, contudo, nomeadamente a partir da década de 1920, alvo principal dos iconoclastas modernistas, que viam nele símbolo maior da literatura 
conservadora e passadista. Retratista da cena carioca na passagem do século XIX para o XX, mas, sobretudo, da ascendente burguesia de Botafogo, Coelho Neto procura representar em sua produção literária, especialmente em seus muitos romances, a "evolução" de uma classe social que, a olhos vistos, ganhava cada vez maior expressão e importância num contexto de crescente sociabilidade urbana. E o cinema, com certeza, atuava de modo decisivo para a consolidação dessa realidade...

Ele está presente, por exemplo, na trama de alguns de seus romances, como O Polvo (1924), em que projecções cinematographicas se alternam com o mundo extático da alta burguesia urbana (NETO, 1924); ou como Esfinge (1906), em que parcas cenas relacionadas ao cinema surgem em meio a uma história de mistério. Mas são seus contos e crônicas que, como se era de esperar, conseguem captar no momento exato do fenômeno, a importância do cinema no dia a dia das grandes cidades do início do século XX. Na pena do autor maranhense, o cinema surge invariavelmente vinculado às futilidades da vida mundana, em geral influenciando o comportamento feminino e quase sempre servindo de exemplo negativo a uma sociabilidade suspeita, superficial e efêmera, como se verifica nos contos dialogados de seu livro Conversas (1922) (NETO, 1922a). Já nas crônicas de O meu dia (1922), do mesmo ano, o autor não hesita em fazer críticas aos próprios filmes a que assiste, afirmando-se, assim, como um de nossos primeiros críticos cinematográficos, embora bissexto. Critica, por exemplo, uma película sobre a vida da rainha Cleópatra, acusando, ironicamente, a presença "em certos episodios sertanejos, muito ao sabor yankee, os arremessados cows-boys [sic], que tudo resolvem à pata de cavallo e tiros" (NETO, 1922b, p. 112). E em passagem sintomática da crítica que se fazia, na época, à novidade que era o cinema, Coelho Neto estende suas diatribes aos efeitos deletérios que as fitas cinematográficas podem ter na educação do povo:

\footnotetext{
"Se o cinematographo, divulgador de maravilhas é, conforme affirmam os que o preconisam, um espelho, sê-lo-á, mas não o da Verdade, se o julgarmos por esse em que se reflecte a feiticeira do Nilo. Projectando os argumentos na tela dentro de scenarios tomados na propria natureza ou adereçados com fidelidade archeologica, como se dá no film a que me refiro, póde o industrial alliar o util ao agradavel, instruindo o povo, mas illude-o, indu-llo em erro, impingindo-lhe ridiculos arremedilhos com 0 titulo enganador de illustrações da Historia" (NETO, 1922b, p. 113).
} 
Elysio de Carvalho (cujo nome verdadeiro possui a grafia Elísio de Carvalho) foi um alagoano que viveu intensamente o grand monde carioca do início do século XX, como jornalista, cronista e poeta. Curiosa e contraditoriamente, envolveu-se com o movimento anarquista brasileiro e - ao lado de nomes como os de Curvelo de Mendonça e Fábio Luz - com o operariado organizado naqueles anos em que o sindicalismo dava seus primeiros passos em nosso país, defendendo inclusive uma literatura de cunho mais social, como se pode entrever em seu livro As Modernas Correntes Estheticas na Literatura Brazileira (1907). A contradição fica, assim, por conta da devoção do autor a certos modismo de então, como o apego desmedido à vida mundana que tinha na Europa em geral e na França em particular seu principal modelo. Por isso, seja pelas páginas efêmeras de nossos periódicos, seja por narrativas literárias mais ou menos representativas dessa realidade urbano-burguesa, não se economizavam evocações daquela Cidade-Luz que tanto atraia nossa sociedade letrada, como revelam algumas passagens daquele que talvez tenha sido seu mais conhecido livro, sintomaticamente intitulado Five o' Clock (1909).

Semelhante contradição pode, contudo, ser explicada no plano do contexto histórico em que vivíamos naquelas primeiras décadas de novo século, refletindo uma espécie de aliança não declarada entre a expressão artística e a sociedade pretensamente aristocrática, redundando na categorização da literatura como "expressão das elites". Esse fato foi exposto de maneira bastante clara por Arnoni Prado, exatamente ao estudar a obra de Elysio de Carvalho:

\footnotetext{
"alinhando-se como um instrumento à disposição das elites, a literatura coloca-se virtualmente sob a influência do autoritarismo ambíguo, mas sempre radical [...] Nesse sentido, próximo do espírito autoritário que sacraliza o saber das elites, o espaço da literatura tende a se definir, no projeto restaurador da Primeira República, como uma instância mediadora que assume a neutralidade para diluir a crise, colhendo, assim, a contrapartida de que a ignorância do povo justifica a necessidade de dirigi-lo e educá-lo do alto" (PRADO, 1979, p. 05).
}

Apesar desse pretenso aristocratismo de Elysio de Carvalho, o cronista não hesitava em atacar exatamente aqueles que simbolizavam, na teoria e na prática, os aristocratas acadêmicos, em especial os poetas parnasianos, posição até certo ponto estranha num radical de ocasião (CÂNDIDO, 1980) mais afeito às superficialidades da vida mundana e aristocrática do que a uma autêntica 
literatura militante: condenando os parnasianos por "reduzir(em) a arte a uma simples questão de fórma", constata que por substituírem "o culto da Idéa pela Idolatria da Fórma, nunca foram nem serão artistas" (CARVALHO, 1907, p. 54).

No que compete ao cinema, ele se insere exatamente na descrição desse universo mundano e burguês, academicamente "aristocrático", próprio das cidades grandes em sua vertiginosa dinâmica sociocultural, que passa diante dos olhos do autor "com a rapidez das fitas cinematographicas" (CARVALHO, 1909, p. $58)$.

Outra personalidade de renome nesse universo em que o cinema emerge como fenômeno mais palpável de uma realidade em transformação é o jornalista, romancista e dramaturgo João do Rio, pseudônimo do acadêmico carioca João Paulo Emílio Cristóvão dos Santos Coelho Barreto ou simplesmente Paulo Barreto. Ligado à Academia Brasileira de Letras e, portanto, ao seu ideário estético, João do Rio abre, com sua entrada naquela instituição, em 1910, as portas para gêneros literários "menores", como a reportagem, a entrevista, 0 folhetim e, sobretudo, a crônica, embora ainda se esboçasse, nos limites da própria Academia, certa resistência a seus cultores, optando-se por manter fidelidade aos modelos mais tradicionais, como o romance e o soneto. De qualquer maneira, tal incorporação resultou na valorização da crônica jornalística como expressão autenticamente literária, quando o próprio jornalismo alcança o estatuto de gênero literário (LIMA, 1990; OLINTO, 1955).

O cinema, logicamente, beneficiou-se também dessa situação, já que nunca fora visto como expressão estética tradicional, como o fora a própria literatura. E na condição de expressão "popular", sobretudo como forma de lazer das classes médias urbanas, era assunto recorrente das crônicas que se produziam com frequência naquelas primeiras décadas do novo século.

Não por outro motivo, João do Rio preferiu reunir suas crônicas em livro intitulado Cinematographo (1909), compilando textos que são, ao mesmo tempo, um elogio e uma crítica irônica à incipiente modernidade. Utilizando-se de uma linguagem dinâmica, tão vertiginosa quanto a própria realidade que descrevia no calor da hora dos acontecimentos, trata de temas variados, apresentando ao leitor um quadro vivo da realidade do momento. Sobre o cinema, vincula-o à modernidade, porém, diferentemente dos demais cronistas de sua época, não 
procura desqualificá-lo ou criticá-lo sob o impulso de valores morais ou à guisa de fazer, por meio dele, uma crítica à sociedade como um todo. Prefere, antes, apontar seus vínculos com a sociedade que se moderniza e se urbaniza a passos largos. Nesse sentido, a apresentação com que abre seu livro de crônicas é primorosa, tanto pelos ataques aos "esthetas de atrazada percepção", que desdenham o cinematographo, quanto pelos elogios a essa manifestação artística "bem modern[a] e bem d'agora" (RIO, 1909, p. VII). De fato, para o célebre cronista, o cinema tem a vantagem, entre outras coisas, de ser uma espécie de registro vivo do presente, atuando "como o arrolador da vida actual, como a grande historia visual do mundo" (RIO, 1909, p. IX).

\section{Conclusão}

Em seu consagrado estudo sobre as cidades latino-americanas, Ángel Rama alude ao aparecimento, na passagem do século XIX para o XX do que chama de cidade modernizada, lembrando que, nesse novo contexto, algumas instituições - como a imprensa - se beneficiaram das "ampliações letradas da modernização" (RAMA, 2015, p. 75). Os autores aqui citados - com especial destaque para Coelho Neto, Elysio de Carvalho e João do Rio - fizeram parte desse conjunto de intelectuais que ajudaram a levar a letra à condição de elemento propulsor da ascensão social, como sugere Rama. E embora o cinema não fosse, ainda, a expressão mais conhecida e cultuada dessa cidade modernizada, que se impunha a olhos vistos, caminhava a passos largos para se tornar expressão prevalente e quase onipresente nos grandes centros urbanos, tornando-se, posteriormente, arte de reprodução de massa, devendo muito de sua natureza ao desenvolvimento da cidade (ZIMERMANN, 2009).

\section{Projecções cinematographicas: cinema in the chronicles of the Brazilian pre-modernism}

ABSTRACT: This article analyzes the representation of cinema in pre-modernist Brazilian literature (short stories, chronicles, novels and poetry), at a time when cinema was only beginning its long journey in the Brazilian cultural scene. It is, therefore, an approach, through culture and history, of the process of modernization of the Brazilian city and society. 
KEY WORDS: Brazilian culture. Pre-modernist literature. Cinema. Modernization.

\section{Referências bibliográficas}

ARAÚJO, Rosa Maria Barboza de. A Vocação do Prazer. A Cidade e a Família no Rio de Janeiro Republicano. Rio de Janeiro, Rocco, 1993.

ARAÚJO, Vicente de Paula. A Bela Época do Cinema Brasileiro. São Paulo, Perspectiva, 1976.

BERNARDET, Jean-Claude. "Acreditam os Brasileiros nos seus Mitos? O Cinema Brasileiro e suas Origens". Revista Usp, São Paulo, No. 19: 17-23, Set./Out./Nov. 1993.

BOURGIN, Georges. La Troisième République. 1870-1914. Paris, Armand Colin, 1967.

CÂNDIDO, Antonio. "Radicais de Ocasião". Teresina etc. Rio de Janeiro, Paz e Terra, 1980, p. 83-94.

CARVALHO, Elysio de. As Modernas Correntes Esthéticas na Literatura Brazileira. Rio de Janeiro, Garnier, 1907.

. Five o’ Clock. Rio de Janeiro, Garnier, 1909.

FABRIS, Mariarosaria. "Cinema: da Modernidade ao Modernismo". In: FABRIS, Annateresa (org). Modernidade e Modernismo no Brasil. Campinas, Mercado de Letras, 1994, p. 97-110.

LIMA, Alceu Amoroso. O Jornalismo como Gênero Literário. São Paulo, ComArte/Edusp, 1990.

METZ, Christian. A significação do cinema. São Paulo, Perspectiva, 2004

NEEDELL, Jeffrey D. Belle Époque tropical: sociedade e cultura de elite no Rio de Janeiro na virada do século. São Paulo, Companhia das Letras, 1993.

NETO, Coelho. Conversas. Contos Dialogados. Rio de Janeiro, Annuario do Brasil, 1922a.

O Meu Dia. Porto, Lello \& Irmão, 1922b.

. O Polvo. São Paulo, Jornal do Comércio, 1924.

OLINTO, Antônio. Jornalismo e Literatura. Rio de Janeiro, Imprensa Nacional, 1955. 
PRADO, Antonio Arnoni. Lauréis Insígnes no Roteiro de 22. São Paulo, FFLCH/USP, 1979 (Tese de Doutorado).

RAMA, Angel. A cidade das letras. São Paulo, Boitempo, 2015.

RIO, João do. Cinematoghrapho (Chronicas Cariocas). Porto, Chardron, 1909.

SÜSSEKIND, Flora. Cinematógrafo de Letras. Literatura, Técnica e Modernização no Brasil. São Paulo, Companhia das Letras, 1987.

ZIMERMANN, Giovana Aparecida. "O lugar do outro: a imagem dos traçados urbanos como técnica de separação". Outra travessia, Florianópolis, Universidade Federal de Santa Catarina, No. 08: 45-53, 2009.

WEBER, Eugen. França fin-de-siècle. São Paulo, Companhia das Letras, 1989.

Data de Submissão: 12/03/17

Data de Aprovação: 06/05/17 